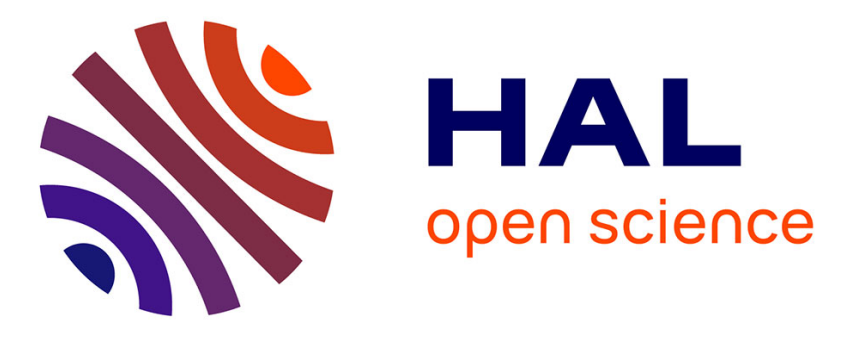

\title{
Experimental measurements of propagation characteristics for maritime radio links
}

Yvon Le Roux, Jacky Ménard, Claude Toquin, Jean-Pierre Jolivet, Fabien Nicolas

\section{- To cite this version:}

Yvon Le Roux, Jacky Ménard, Claude Toquin, Jean-Pierre Jolivet, Fabien Nicolas. Experimental measurements of propagation characteristics for maritime radio links. ITST'09: 9th International Conference on Intelligent Transport System Telecommunication, Oct 2009, Lille, France. pp.364 369. hal-02316688

\author{
HAL Id: hal-02316688 \\ https://hal.science/hal-02316688
}

Submitted on 15 Oct 2019

HAL is a multi-disciplinary open access archive for the deposit and dissemination of scientific research documents, whether they are published or not. The documents may come from teaching and research institutions in France or abroad, or from public or private research centers.
L'archive ouverte pluridisciplinaire HAL, est destinée au dépôt et à la diffusion de documents scientifiques de niveau recherche, publiés ou non, émanant des établissements d'enseignement et de recherche français ou étrangers, des laboratoires publics ou privés. 


\title{
Experimental measurements of propagation characteristics for maritime radio links
}

\author{
Yvon-Marie Le Roux, Jacky Ménard, Claude Toquin, Jean-Pierre Jolivet, Fabien Nicolas \\ Institut Télécom - Télécom Bretagne, UMR CNRS 3192 Lab-STICC, Brest, France \\ Email: yvon.leroux@telecom-bretagne.eu
}

\begin{abstract}
This paper presents studies, carried out by Télécom Bretagne, concerning new radio technologies (mainly WiMAX, $802.16 \mathrm{e}$ ) in the maritime environment. The aim of these studies is to reinforce the quality and the robustness of such transmissions. Several measurements were set up to characterize the propagation channel in maritime environment in order to study the communication performances of WiMAX. This characterization was obtained by specific experimental devices, developed and implemented by Télécom Bretagne. The experimentations were carried out at frequencies of $3.5 \mathrm{GHz}$ (Licensed WiMAX Band in France) and $5.8 \mathrm{GHz}$ (Free Band in France). Similar studies [1] and [2] were already carried out, but they did not take into account all the environment characteristics, namely tides and coast relief masking. Our study looks at these parameters for a better understanding of the propagation in operational transmission environments. In this paper, measurements were carried out by measuring the mean received power both for several distances over the sea and for a coastal point-to-point link during long periods. Part of the work presented in this paper has been obtained during the Ex'treme project.
\end{abstract}

Index Terms: propagation channel measurements, maritime environment, two-ray model, WiMAX.

\section{INTRODUCTION}

As mentioned in [2] and [3], a basic model being able at a first order to apply to the propagation in maritime environment is the two-ray model. This model takes into account one direct path between the transmitter and the receiver and another path refracted by the sea. For this model, it is possible to calculate the level of the received field at a given point, according to: the distance between the transmitter and the receiver, the relative heights of the transmitter and the receiver from the sea, the wave polarization, the working frequency, the conductivity, the relative permittivity of the sea and the transmitted power.

The present study aims at evaluating the levels of accuracy of this model and at examining two other causes of modification of the propagation channel:

- the masking effects due to the coastal relief and islands situated between the transmitter and the receiver,
- the tide effects that modifies the refraction conditions of the indirect path.

The paper will show various propagation characteristics observed during our experiments.

\section{MEASUREMENTS}

\section{A. Measurement Locations}

The measurements were carried out in the Brest harbour. The navigation conditions were good. Indeed the climate was gentle and the waves not very high. Figure 1 represents the locations where the measurements were carried out and an example of two routes covered by the boat with transmitting equipments (in yellow the forward route and in white the backward route). The point 1 (IFREMER site) indicates the receiver location for all the experimentations and the point 2 (Le Caro site) notices one other spot, in order to have a pointto-point fixed connection above the sea. The Brest harbour presents various types of environments, also defined in paper [4] in which four types of environments and five groups of measurements are mentioned.

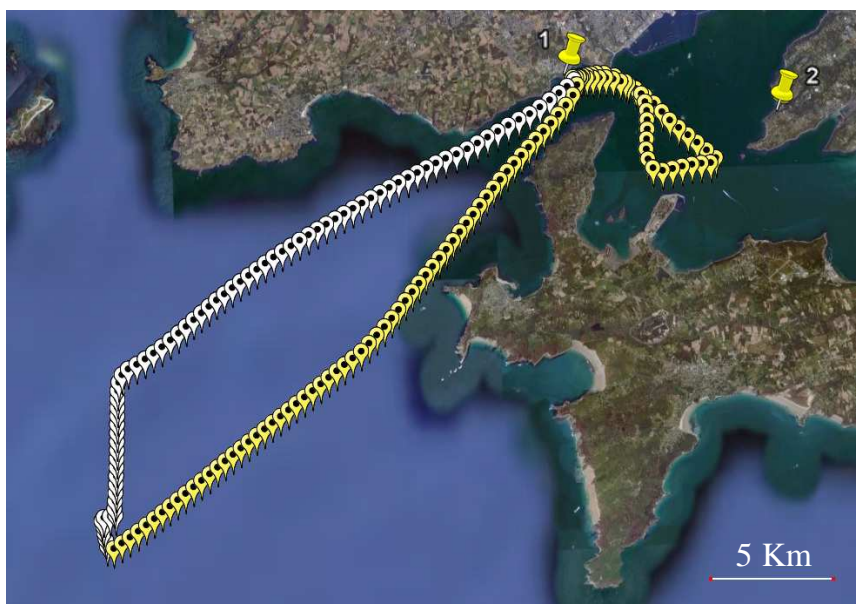

Fig. 1. Example of routes (Max Tx-Rx distance = 27 km).

\section{B. Measurement Equipments}

At the transmitting site (the boat), two kinds of signals may be generated: a continuous sine wave or a pulsed one. The system involves two generators, one for the carrier frequencies $3.5 \mathrm{GHz}$ or $5.8 \mathrm{GHz}$ and the other one for the pulse shaped 
signals. The pulsed wave is built with a switch and a band pass filter. Two horn antennas are installed on the boat, the first at a height of 12 meters above sea level and the second one at a height of 3 meters above sea level. At the receiving site, two systems were available, namely a spectrum analyzer controlled by a computer and a second system build with PXI cards. A controller, a signal analyzer, a frequency converter and a data storage device constituted this last one. This acquisition system can record the received signal with $80 \mathrm{~dB}$ magnitude range and a $20 \mathrm{MHz}$ bandwidth centred on a programmable frequency included between a few tens $\mathrm{kHz}$ and $6 \mathrm{GHz}$.

These two systems received the signal transmitted by means of a horn antenna followed by a filter and a low noise amplifier. This antenna was placed at the point number 1 with a height of 52 meters.

The antennas were $12 \mathrm{~dB}$ horn antennas with $120^{\circ}$ horizontal aperture and $30^{\circ}$ vertical aperture. A GPS equipped a PC on the boat. The time and the position data were recorded for each trip. These data make possible to readjust the recordings of the signal received according to the real distance between the transmitter and the receiver. These data were confirmed by the equipment of the ship. The GPS information was also used for clock synchronization of the Tx an Rx devices.

The following pictures represent the devices used for the experimentations.

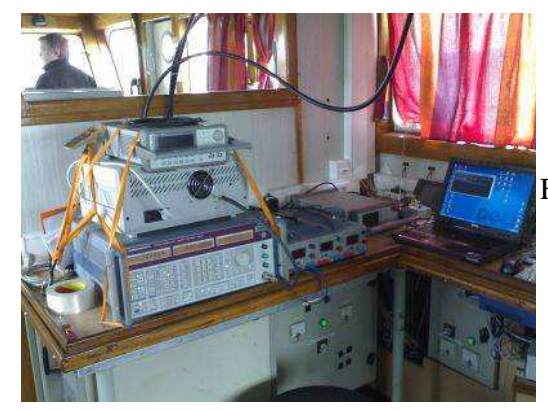

Fig. 2. Transmitting devices

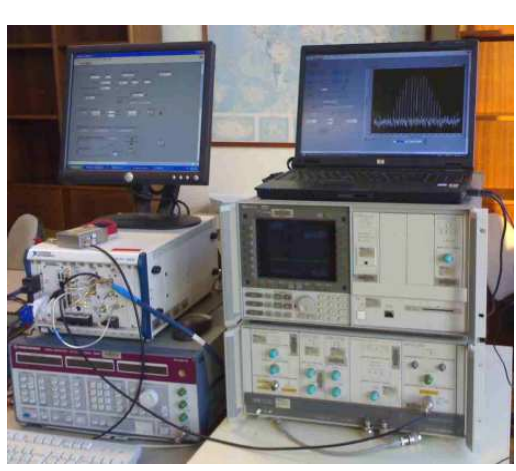

Throughout this paper, all the presented results concern the $3.5 \mathrm{GHz}$ frequency.

\section{MEASUREMENT RESUltS}

\section{A. Theoretical Results}

As indicated in the introduction a basic model being able to apply to the propagation in maritime environment is the tworay model. It takes into account a direct way between the transmitter and the receiver and a way refracted by sea surface. We consider this model for simulate the propagation over the sea, the figures 4 and 5 show simulation examples.

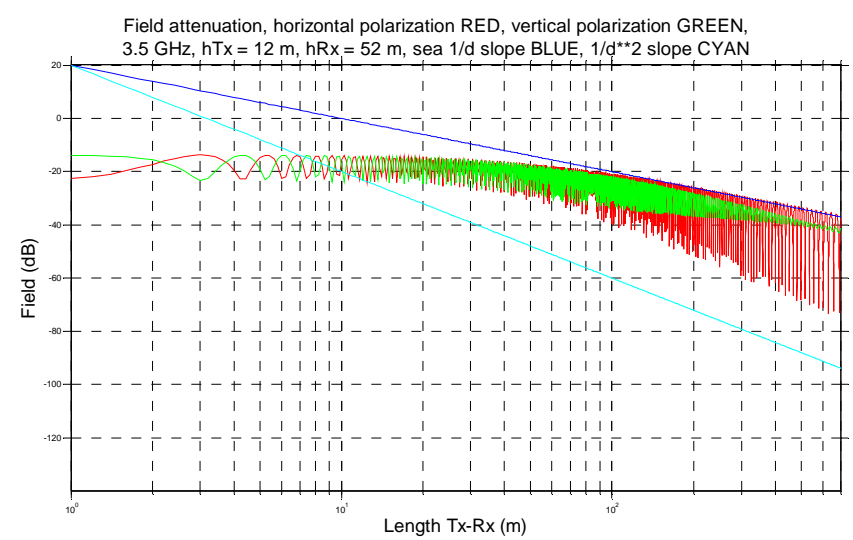

Fig. 4. Simulation with two-ray model: level of the received field according to the length Tx-Rx.

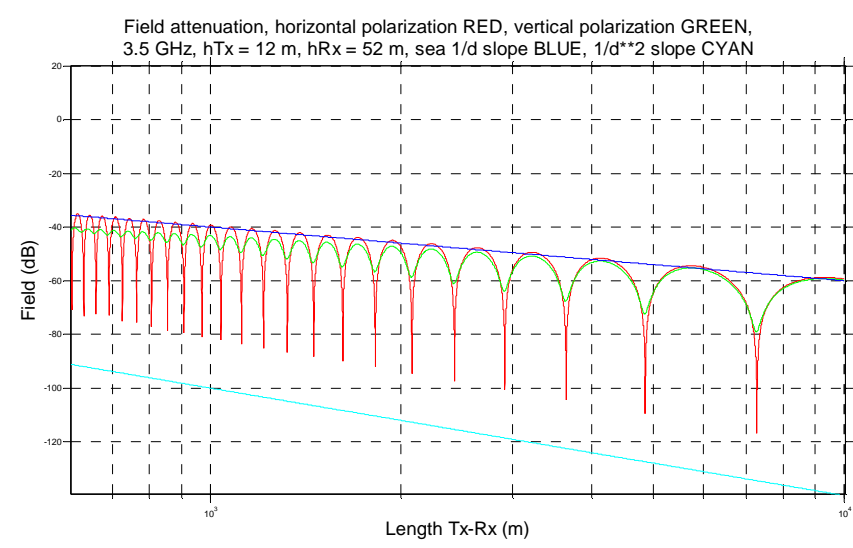

Fig. 5. Simulation with two-ray model: level of the received field according to the length Tx-Rx.

From the simulated results we can notice what follows:

- the average slope of path loss is proportional to the TxRx distance approximately up to the radio electric horizon, as for a connection in free space,

- the average slope of path loss is proportional to the squared of the Tx-Rx distance, approximately beyond the radio electric horizon,

- the horizontal polarization presents major and recurrent fading (up to $60 \mathrm{~dB}$ ) depending on the Tx-Rx distance,

- the vertical polarization presents major and recurrent fading (up to $30 \mathrm{~dB}$ ) depending on the Tx-Rx distance,

- the fading of horizontal and vertical polarizations are phase opposite until a distance of few hundred meters,

- the distance interval between fading for both the horizontal and vertical polarizations exceeds the hundred meters for transmitter-receiver distances greater than approximately $1 \mathrm{~km}$.

\section{B. Experimental Results}

These preceding characteristics were verified during experiments and some measurement results are presented now. 
Geographical representations have been obtained from "Google Earth".

Figure 6 represents an example of route during which measurements were carried out.

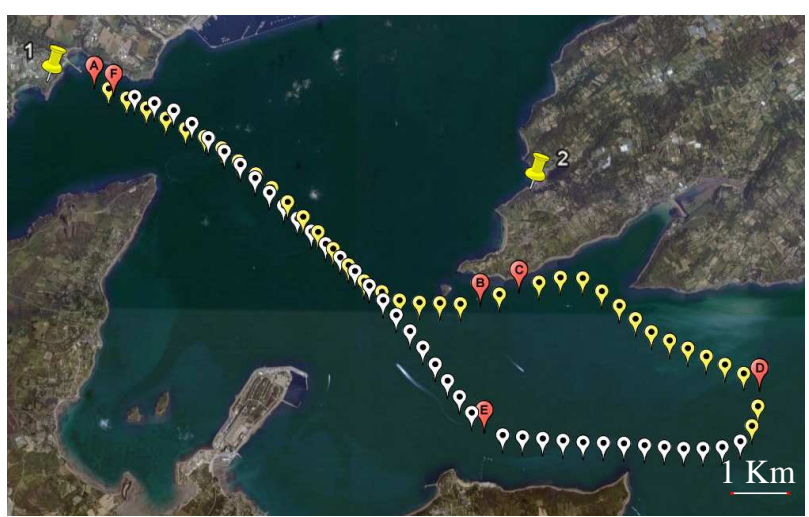

Fig. 6. Example of route where the measurements were carried out $($ Max Tx-Rx distance $=14 \mathrm{~km})$.

The following figure shows measurement results for the level of the received field, on this "mixed" course, corresponding to the two-ray model previously described but involving also some partial or total masking effects.

Results shown figure 7 compares the levels of theoretical values from the two-ray model, and measured ones of the received signal for a distance from $\mathrm{A}$ to $\mathrm{C}$.

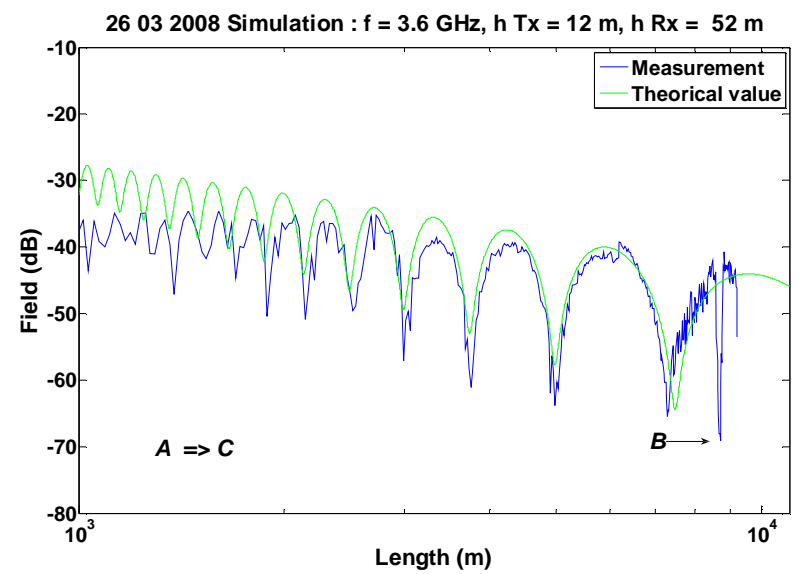

Fig. 7. Level comparison of the measured received signal with simulated values. In blue: measurements, in green: simulations

There is a good agreement between the theoretical values of field attenuation and the measurements. The level differences at the beginning of the travel are mainly due to antenna effects. Indeed, the Tx and Rx antennas has only 30 degrees vertical apertures, and the receiving antenna at point $\mathrm{A}$ was located at 52 meters above the sea, whereas the transmitting antenna was onboard a small ship. The sharp level fluctuation at the end of the record (position B) is a masking effect due to a small island.

For a better understanding of the masking effects, other experimentations were realized. The following figures show some obtained results. Figure 8 shows a trip with an important masking effect and figure 9 shows the measurement results received field levels on this way.

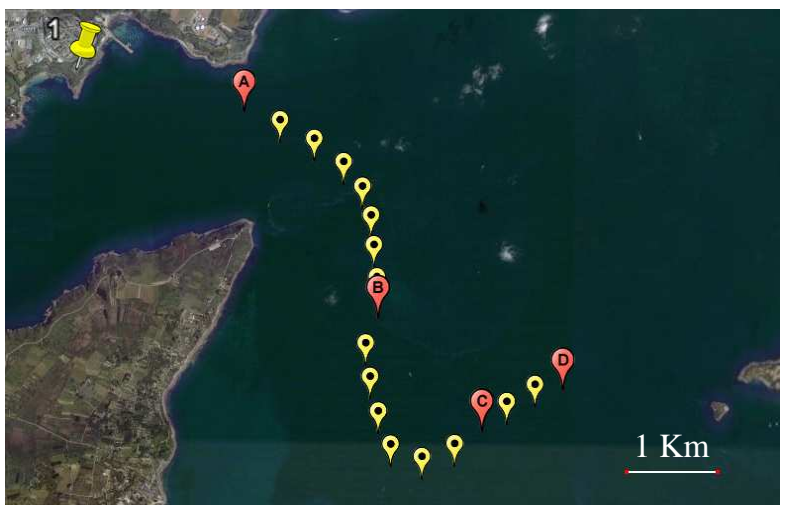

Fig. 8. Example of route with an important masking effect.

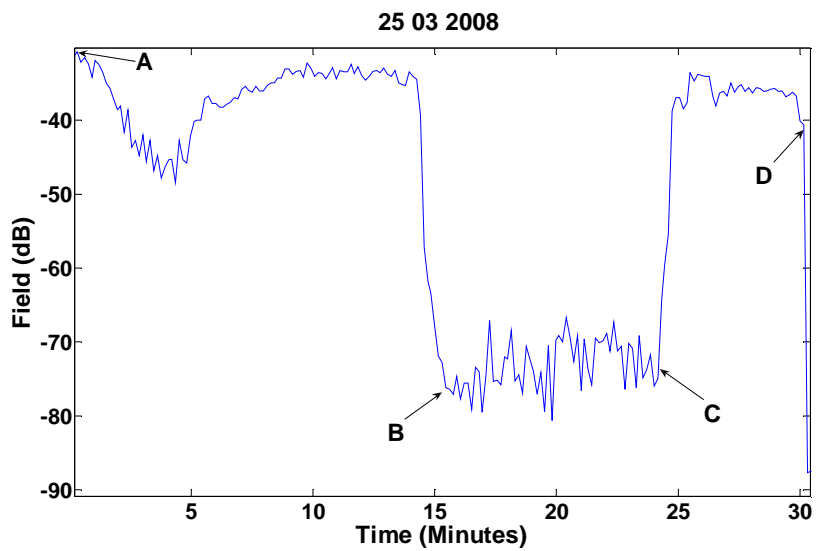

Fig. 9. Received field level with an important masking effect.

Sailing behind and near from point B causes a sudden fading of the field level (approximately $40 \mathrm{~dB}$ ). The cause of this is the important height of this obstacle (76 meters). Other experimentation is shown with the figures 10 and 11 . It is a long way where an important cliff is located between the starting point and the arriving point.

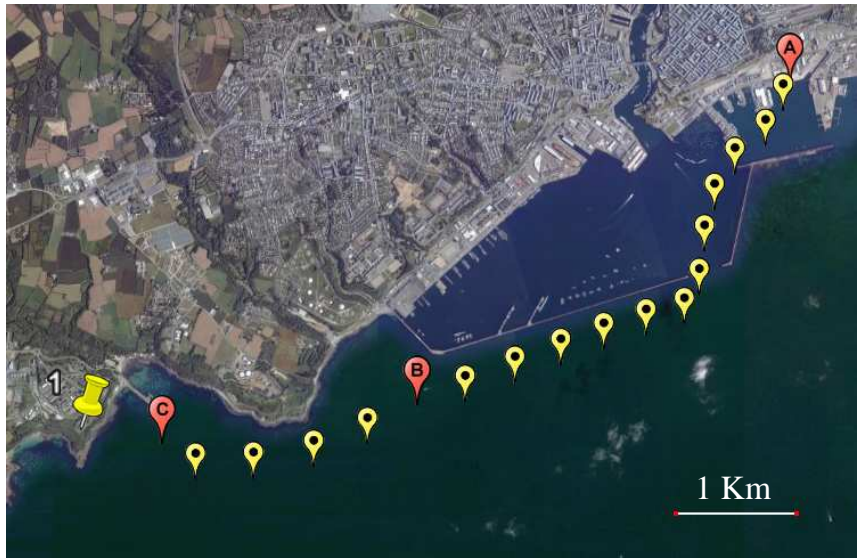

Fig. 10. Example of measurement location with an important masking effect. 


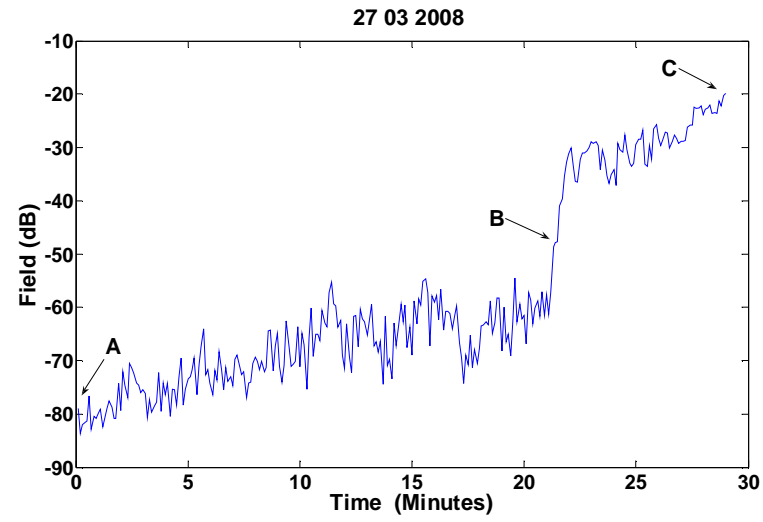

Fig. 11. Level received field with an important masking effect.

Here two effects are opposed: increase of the field level with the reduction of the transmitter-receiver distance and the masking effect growing when the boat gets closer the coastal point. In this configuration, it is the first that prevails slightly. At the point $\mathrm{B}$, the mask effect causes a reduction of $25 \mathrm{~dB}$ as previously indicated to the passage behind the island.

\section{Tide effects}

In the two-ray model, the relative heights of $\mathrm{Tx}$ and $\mathrm{Rx}$ antennas are important characteristics in calculation equation. In our situation, the effective antenna heights of course varied with the tide effects, which imply a modification of the indirect path. To evaluate this phenomenon the figure 12 presents the results of the field level received over a radio link between Tx and $\mathrm{Rx}$ on the ground, but above sea. Figure 13 presents the hours of tides corresponding to the measurement period.

These figures show the strong incidence of tides on the point-to-point fixed connection above sea. We note that for this link geometry, the maximum of the field levels were obtained for tide heights from approximately 1 and 6 meters. The minimum of the field levels were obtained for tide heights from approximately 2.5 meters.

Other descents of the field levels occur near 7 meters of tide heights, indicating that in the event of strong tide (over 8 meters), a minimum of field level would again be reached.

Other complementary results confirm the influence of the sea state but this influence requires to be better quantified by new studies and experiments.

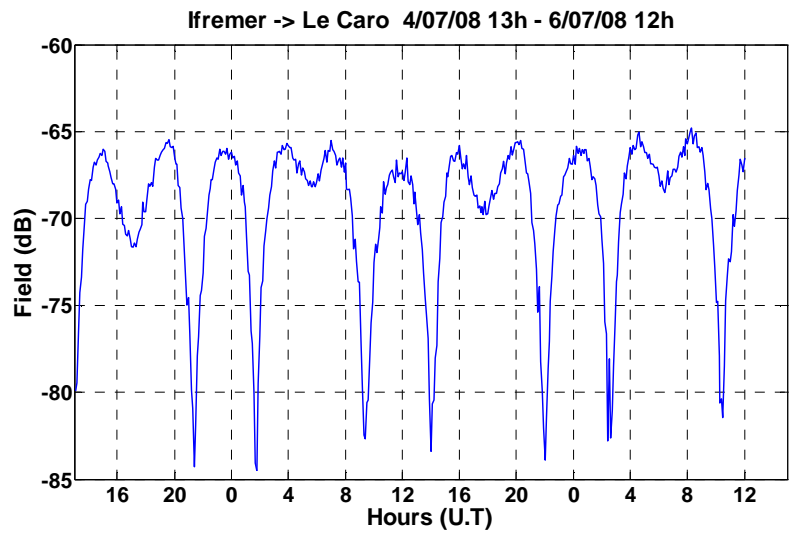

Fig. 12. Received field level according to the Universal Time.

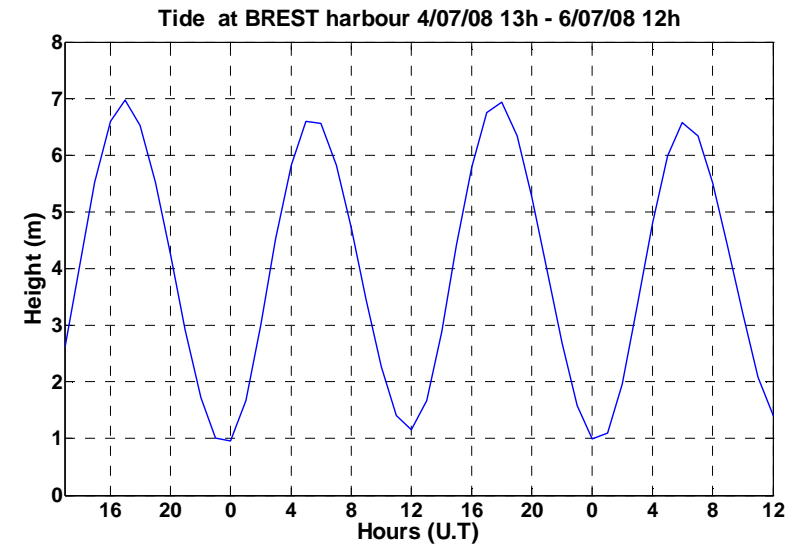

Fig. 13. Tide according to Universal Time.

Obviously, these tide effects also exist for radio links between a boat and the ground and should be taken into account.

\section{DATA ANALYSIS AND SYSTEM IMPACTS}

The theoretical results and the experimental validations show that the propagation channel in maritime environment has diversity at three dimensions:

- a polarization diversity which is present until distances ranging between 10 meters and 500 meters. Experimental studies in cross polarizations must be made to consolidate this observation,

- the vertical polarization mode is better adapted starting from distances of a few hundred meters,

- a horizontal space diversity (and temporal for a transmitter and/or a receiver in mobility). This diversity, inversely proportional to the $\mathrm{Tx}-\mathrm{Rx}$ distance is thus reduced with this distance,

- a vertical space diversity proportional to the relative height variations of the transmitting and receiving antenna.

The results confirm also that the masking effects are more or less important according to the distance relatives to the masks. Moreover, the influence of the sea states is certain on two levels and request still to be quantified in experiments:

- pointing defaults of the receiving and/or transmitting antennas [5] and [6],

- modification of the refraction conditions of the indirect way.

Studies and experimental complements are necessary to refine the description of the channel behaviour, in particular for the presence of obstacles (coastal relief, large ship ...) near one or both connection ends, being able to create complex situations of multi-paths.

To take benefit from these diversities of the propagation channel in maritime environment, the following solutions on the systems could be examined:

- throughput and/or emission power adaptability according to the reception level and/or the signal to noise ratio (thus depending from distance and masking effects),

- taking advantage of the natural channel diversity: 
using two transmitting and/or two receiving antennas with orthogonal polarizations (vertical and horizontal), with a reception strategy to be determined (combining, best level, ...). This solution would be useful until approximately $1000 \mathrm{~m}$ (in harbour and harbour approach). Beyond $1000 \mathrm{~m}$, vertical polarization is preferable,

- take advantage from channel horizontal diversity by using two (or more) receiving antennas approximately distant of half of the maximum interval between two fading, with a reception strategy to be determined (combining, best level, ...). But the effectiveness of the solution depending on the Tx-Rx distance is proportional to the size of the ships concerned.

- exploit the channel vertical diversity by using two (or more) transmitting antennas and/or two (or more) reception antennas separated by the height from approximately half of the maximum interval between two fading in altitude, with a reception strategy to be determined (recombination, best level, ...). Vertical and polarization diversities could be combined. The solution would be effective for connections between two points at ground and above the sea, for connections between a ground point and a ship, and for connections between two ships, with however a respectively decreasing efficiency for these three cases.

- control the Tx-Rx antenna pointing.

\section{LINKED MARITIME PROJECTS}

\section{A. Ex'treme project}

This project proposes the implementation of a broadband connectivity between the ground and the ships on sea. It will offer broadband services, mainly to increase the safety on the sea and to exchange information at short distances from the coast.

Moreover this project is based on complementary radio technologies to ensure IP services towards the passengers and the members of crew. The Ex'treme project is pioneer in the sector of the broadband services on the sea. This is because the existing IP Mobile service offers are not yet really dedicated to the maritime field.

The public concerned is mainly: pleasure boats, passenger liner, fishing vessels and ships of service. Moreover a great range of services will be proposed to these users: information on safety, the management and diffusion of an alarm, video transmissions, video monitoring, videoconference and applications of collaborative work, Internet access...

The partners of this project are: Alcatel Business Systems, Thomson-GrassValley, IFREMER, C2 Innovativ'Systems, Morgan'Conseil, Chantiers de l'Atlantique, and Télécom Bretagne.

\section{B. ImaginLab project}

ImaginLab project is a test and experimental regional platform, adopted by FUI 6. It will make it possible to test new products and services. The infrastructure design and installation are carried out jointly by the pole Images \& Réseaux and the UEB (Université Européenne de Bretagne), this later one having delegated its mission to Télécom Bretagne.

The infrastructure is made up of three inter-connected technological platform. The "Internet du futur" platform, located in Lannion, works on IMS (IP Multimedia Subsystem) architecture. The "Images en mobilité" platform, located in Rennes, will be used to diffuse mobile television services. The "haut débit sans fil" platform, located in Brest, will make it possible to test high-speed services on radio links, such as applications intended for the professionals or accessible services from a boat located near the coasts.

In this project, Télécom Bretagne uses its knowledge in the wireless transmission domain. These studies will relate to the wave propagation studies in different environments (urban, suburban, white zones and maritime areas).

\section{Palmyre project}

The Palmyre project consists in a realization of a modular platform for the evaluation of both systems and new communication concepts in frequency bands going from HF to microwaves, within realistic experimental situations.

This platform is being developed by a hardware and software infrastructure group

Partners of this project are teams from the "Institut d'Électronique et de Télécommunications" in Rennes, the "Laboratoire d'Électronique des Systèmes Temps Réel" from University of Bretagne Sud, the "Micro-ondes, Electronique and Signal \& Communications departments" from Télécom Bretagne and the "Université de Bretagne Occidentale" in Brest.

\section{Navtrack project}

The general concept of this project is constituted of two technical guidelines:

- the first consists in locating in real-time all the boat race actors, using a radio transmission $(868 \mathrm{MHz})$ to transmit GPS data, which are decoded on ground. A suited cartography traces the trajectories. The virtual images are enriched by environmental data (wind, currents, tide...)

- the second aims at transmitting on line the images of the boat race by a radio transmission at $5.8 \mathrm{GHz}$.

Partners of this project are teams from "DETI", "Ecole Navale - IRENav", "AGESSI", "Technopole Brest Iroise", "Electronique department from Télécom Bretagne" in Brest and from "SeatizenPro" in Villeneuve-Loubet.

\section{CONCLUSION AND PERSPECTIVES}

This paper presented experimental researches carried out by the CaPSyS team of Télécom Bretagne on the new radio technologies in the maritime environment. This characterization of the propagation channel is necessary to 
understand the behaviour of radio waves in a maritime environment. Moreover, with this study, the performances of WiMAX systems can be analyzed according to the characteristics enumerated above. It is thus possible to take advantage of this analysis to propose some improvements of the transmission systems for better performances.

Télécom Bretagne develops new testing systems, in particular multi-channel receiving and transmitting systems, in order to explore the channel diversities quoted previously (MIMO spatial and polarization diversities) and for a better understanding of the propagation mechanisms in operational transmission environments (terrestrial as well as maritime). WiMAX (or others) transmission systems will also be operated simultaneously with channel sounding equipments, in order to compare the propagation channel characteristics with transmission performances.

These studies have been partially funded by: Brittany Regional Council, Finistere Council, Brest Metropole Oceane and Europe (FEDER).

\section{REFERENCES}

[1] J. Joe, S.K. Hazra, S.H. Toh, M.W. Tan, J. Shankar, V.D. Hoang, M. Fujise, "Path Loss Measurements in Sea Port for WiMAX", Wireless Communications and Networking Conference, 2007. WCNC 2007. IEEE, 11-15 March, 2007.

[2] Rosario G. Garroppo, Stefano Giordano, Davide Iacono, Alessandro Cignoni, Matteo Falzarano, "Wimax Testbed For Interconnection Of Mobile Navy Units In Operational Scenarios", Military Communications Conference. MILCOM 2008. IEEE, 16-19 Nov, 2008.

[3] Yattoun, I.; Labia, T.; Peden, A.; Landrac, G.; Ney, M.; Resibois, M.; Bonnin, J.M.; Baghdadi, A.; Montavont, N.; Fujise, M.; Le Roux, Y, “A Millimetre communication system for IVC", ITST $07,7^{\text {th }}$ International Conference on ITS, 6-8 June 2007.

[4] Konstantinos N. Maliatsos1, Student Member IEEE, Panagiotis Loulis1, Michail Chronopoulos, Philip Constantinou1, Member, IEEE Panagiotis Dallas2, Michail Ikonomou, "Measurements and Wideband Channel Characterization for Over-the-sea Propagation", Wireless and Mobile Computing, Networking and Communication, WiMob 2006. IEEE International Conference, 19-21 June 2006.

[5] Su Wen, Peng-Yong Kong, Jaya Shankar, Haiguang Wang, Yu Ge, Chee-Wei Ang, "A novel Frame work to simulate Maritime Wireless Communication Networks", OCEANS 2007, Sept. 29 2007-Oct. 4 2007.

[6] Chee-Wei Ang and Su Wen, "Signal Strength Sensitivity and Its Effects on Routing in Maritime Wireless Networks", Local Computer Networks, 2008. LCN 2008. $33^{\text {rd }}$ IEEE Conference. 